\title{
Life cycle and growth pattern of the endangered myrmecophilous Microdon myrmicae (Diptera: Syrphidae)
}

\author{
MagdalEna WITEK $^{1}$, SARA CANTERINO ${ }^{2}$, Emilio BALLETTO ${ }^{1}$ and Simona BONELLI ${ }^{1}$ \\ ${ }^{1}$ University of Turin, Department of Biology, Life Sciences and Systems Biology, Via Accademia Albertina 13, 10126 Turin, Italy; \\ e-mails:mawitus@yahoo.co.uk, emilio.belletto@unito.it, simona.bonelli@unito.it \\ ${ }^{2}$ University of Turin, Department of Arboriculture and Pomology, Via Leonardo da Vinci 44, 10095 Grugliasco, Italy; \\ e-mail: sara.canterino@unito.it
}

Key words. Syrphidae, hoverflies, Microdon myrmicae, ants, Myrmica, Maculinea, social parasites, larval ecology, polymorphic growth

\begin{abstract}
In Europe there are only a few species of the syrphid fly Microdon, which live in the nests of various genera of ants. For most of these rare flies, details of their biology, larval behaviour and relationships with their hosts are still not yet well known. In this paper we present data on the life cycle, feeding behaviour and growth pattern of Microdon myrmicae, a social parasite of Myrmica ants and compare it with two species of Maculinea butterflies similarly parasitizing Myrmica ant colonies. M. myrmicae has three larval instars and overwinters as a third instar. Eggs and $1^{\text {st }}$ instar larvae are ignored by ants, which indicate that they are "chemically insignificant". $2^{\text {nd }}$ and $3^{\text {rd }}$ instar larvae feed on small ant brood. M. myrmicae larvae grow rapidly from May to July and later in the year the host colony only serves as shelter for overwintering. Like Maculinea alcon, larvae of M. myrmicae are numerous in Myrmica nests and more numerous than those of Maculinea teleius. Since the larvae of Microdon feed on an abundance of young ant brood, they experience low level of scramble competition and although many may develop in an ant's nest they have probably little effect on host colony fitness.
\end{abstract}

\section{INTRODUCTION}

Numerous arthropods, such as beetles, butterflies and syrphid flies penetrate, inhabit and exploit ant societies (Hölldobler \& Wilson, 1990; Thomas et al., 2005). Although it is estimated that there are about 10,000-20,000 species of social parasites of ant's (Thomas et al., 2005) details of the biology and life history traits are known for only a small number of species (Thomas et al., 2005). In Europe, one of the best-studied systems is that of Maculinea van Eecke 1915, butterflies and their Myrmica Latreille 1804, host ants (Settele \& Kühn, 2009). Ants of this genus are also exploited by another social parasite, the syrphid fly Microdon myrmicae Schönrogge et al., 2002 (Schönrogge et al., 2002; Bonelli et al., 2011).

The life cycles of all known species of Microdon are invariably connected with ants. The fly larvae live inside ant colonies and exploit them as food resource and shelter (Elmes et al., 1999). Most species of Microdon live in tropical regions (Cheng \& Thompson, 2008) but some are known to occur in the Palearctic (Andries, 1912; Doczkal \& Schmid, 1999) and Nearctic (Duffield, 1981; Akre et al., 1988). In Europe there are relatively few species, i.e. Microdon miki Doczkal \& Schmid 1999, M. devius (Linnaeus, 1761), M. mutabilis (Linnaeus, 1758), M. myrmicae, M. analis (Macquart, 1842) and M. major Andries, 1912 (Doczkal \& Schmid, 1999; Schmid, 2004; Witek et al., 2011), although their number may be underestimated since social parasites are prone to cryptic speciation (Elmes et al., 1999; Schönrogge et al., 2002). Little is known about the life cycle, habitat preferences and interactions with host ants for most of European species of Microdon, with detailed information on host-ant specificity and habitat requirements known only for M. mutabilis (Elmes et al., 1999; Schönrogge et al., 2002, 2006, 2008). Schönrogge et al. (2002) separated M. myrmicae from M. mutabilis mostly on the basis of some morphological traits of the pupae and host ant specificity. M. myrmicae only exploits nests of Myrmica ants, whereas M. mutabilis is associated with colonies of Formica lemanii Bondroit, 1917 (Schönrogge et al., 2002). Recent investigations in various parts of Europe show that M. myrmicae uses mostly Myrmica scabrinodis Nylander, 1846 although some populations also successfully use colonies of other Myrmica species such as M. gallienii Bondroit, 1920 or M. rubra (Linnaeus, 1758) (Bonelli et al., 2011). Moreover, the same authors demonstrate that the occurrence of $M$. myrmicae is associated with wet, often temporarily waterlogged grasslands dominated by Molinia spp. There is no information, however, on larval development and the way they use resources in ant colonies. In this paper we present data on the life cycle, larval growth pattern and the potential influence of $M$. myrmicae on colonies of its host ant. This information will provide a better insight into the relationships of other European species of Microdon with their hosts.

\section{MATERIAL AND METHODS}

\section{Study area}

The life cycle and larval growth pattern of M. myrmicae were investigated in a population located in a wet meadow dominated by Molinia coerulea, at Caselette near Turin, in northern Italy $\left(45^{\circ} 70^{\prime} \mathrm{N}, 07^{\circ} 29^{\prime} \mathrm{E} ; 360 \mathrm{~m}\right.$ a.s.l.). The site is also inhabited by the butterflies Maculinea alcon (Dennis \& Schiffermüller, 1775) and Maculinea teleius (Bergsträsser, 1779), both of which are obligate parasites of Myrmica ants. The local host ant species of these three parasites is Myrmica scabrinodis, the only Myrmica species present at Caselette. The study site is in the NATURA2000 site "Monte Musine-Laghi di Caselette" (IT1110081).

\section{The life cycle of Microdon myrmicae}

In 2007, 2009 and 2010 adults, larvae and pupae of Microdon myrmicae were collected from the field. At the end of May 2007, four adult females of M. myrmicae were collected and 
TABLE 1. Summary of methods and results used for describing the life cycle and growth pattern of Microdon myrmicae.

METHODS

RESULTS

(1) May 2007: 4 adult females were collected in the field and (1) Eggs (109) and $1^{\text {stinstar larvae (19) behaviour and interaction }}$ reared in the laboratory where they laid their eggs on the surface with ants were observed in the laboratory. of Myrmica nests.

(2) April and May 2008: searching for larvae/pupae/exuvia of (2) Estimation of median number of parasite larvae per host nest. Microdon myrmicae, Maculinea alcon and Maculinea teleius in 131 specimens of M. myrmicae were found in 30 Myrmica nests, Myrmica ant nests. 200 nests were examined. 56 of M. alcon in 15 nests and 19 of M. teleius in 10 nests.

(3) September 2009: 10 larvae were collected in the field, taken to the laboratory, weighed and reared with Myrmica ants until spring 2010.

(3) Feeding behaviour and survival of $3^{\text {rdinstar }}$ larvae were observed in the laboratory and the results were used for describing life cycle.

(4) July-October 2010 and April-May 2011: 29 larvae and 4 pupae were collected in the field, taken to the laboratory, weighed and reared with Myrmica ants. Seven of the larvae collected in July were fed eggs, small and large larvae, and pupae of ants.

(4) Data on body mass of field-collected larvae and pupae were used to describe the growth of the larvae and life cycle. The feeding behaviour of the 7 larvae collected in July was recorded.

taken to the laboratory where they were kept in plastic boxes $(24 \times 5 \times 16 \mathrm{~cm})$ containing grass and colonies of M. scabrinodis. After oviposition, the development of the eggs and behaviour of the $1^{\text {st }}$ instar larvae were observed, as well as the behaviour of the ant workers.

During September and October 2009, ten M. myrmicae larvae were collected and taken to the laboratory together with their host nests. The fly larvae were immediately weighed to the nearest $0.1 \mathrm{mg}$ using a Precisa ${ }^{\circledR}$ digital balance. Each colony containing larvae was placed in a transparent plastic box $(20 \times$ $15 \times 5 \mathrm{~cm}$ ). Part of the box floor was covered with fine plaster, which was moistened with water to maintain a suitable humidity. Once a week, the ants were fed with glucose and frozen Drosophila larvae, and the behaviour of M. myrmicae larvae was observed for half an hour. Myrmica colonies were kept in the laboratory at a temperature of $20^{\circ} \mathrm{C}$ under a natural diurnal light cycle until May 2010.

In July 2010, ten small M. myrmicae larvae were found inside M. scabrinodis nests and taken to the laboratory. Seven of them were reared on a special food regime (see below) in order to observe their feeding behaviour and the other three were kept in plastic boxes together with their original host colonies. All these larvae were exposed to a natural light cycle and kept at a temperature of $20^{\circ} \mathrm{C}$ until they died.

\section{Growth pattern and feeding behaviour of M. myrmicae larvae}

In 2010 at the beginning of larval development M. myrmicae larvae were collected from the field on the following dates to evaluate their growth pattern and feeding behaviour: (i) 25/06 (no larvae), (ii) $05 / 07$ ( 5 larvae), (iii) $16 / 07$ (5 larvae), (iv) $27 / 07$ (5 larvae), (v) 15/09 (5 larvae) and (vi) 14/10 (4 larvae). In 2011 samples were collected at the end of larval development as follows: (vii) 06/04 (5 larvae) and (viii) 12/05 (4 pupae). All larvae and pupae were taken to the laboratory and immediately weighed.

Seven M. myrmicae larvae found in July 2010 were also reared in small artificial Myrmica nests in order to observe their feeding behaviour. Each artificial nest consisted of a transparent plastic box $(5.5 \times 5.5 \times 4 \mathrm{~cm})$ with part of the floor of the box covered with fine plaster, which was moistened with water. Each M. myrmicae larva was reared in a separate box containing: (i) five Myrmica workers, (ii) two ant eggs, and (iii) two small, two medium-sized and two large ant larvae. Both the ant workers and ant brood were from the same nest the Microdon larva was collected from. Fresh food (ant eggs and larvae) was offered and replaced every third day. Observations were carried out until the death of each M. myrmicae larva.

\section{Number of social parasite larvae in Myrmica nests}

Between the end of April and mid May 2008, Myrmica ant nests were opened and searched for evidence of Microdon myrmicae and Maculinea butterflies. At that time of the year the expectation is that there will be fully grown larvae, pupae, or fresh exuviae of M. myrmicae and medium sized larvae of Maculinea butterflies in the ant nests.

Summary of the methods used are presented in Table 1.

\section{RESULTS}

\section{The life cycle of $M$. myrmicae}

In the laboratory a total, 109 eggs (Fig. 1A) were laid on the outer surface of Myrmica nests by four females of M. myrmicae. The M. myrmicae eggs were ignored by Myrmica ants. Two weeks after oviposition, $1^{\text {st }}$ instar larvae (Fig. 1B) started to emerge and quickly entered the ant nest. In no case was any interaction between M. myrmicae larvae and Myrmica ants detected. All laboratory-reared $1^{\text {st }}$ instar larvae died after a few days: the maximum observed lifespan was 13 days. Fieldcollected (July 2010) $2^{\text {nd }}$ instar larvae (Fig. 1C) actively moved into artificial ant nests and on a few occasions feeding behaviour was observed (described below). Laboratory observations indicate that these $2^{\text {nd }}$ instar larvae moulted to the last, $3^{\text {rd }}$ instar larva in July (Fig. 1D). Ten M. myrmicae $3^{\text {rd }}$ instar larvae found in September 2009 were weighed $(134.9 \pm 38.7 \mathrm{mg}$ ) (mean \pm SD) and kept in the laboratory in nests of M. scabrinodis as described above. In no case were they observed feeding and they remained immobile in the outer parts of the artificial nest. Nine of the ten M. myrmicae larvae survived the winter. One pupated at the end of February and the others in March and April (Fig. 1E), and on average adult flies emerged after three weeks (Fig. 1F).

\section{Growth pattern and feeding behaviour of $M$. myrmicae larvae}

No larvae were found at the end of June because at that time they are too small to be detected in the field. The mean body mass ( $\pm \mathrm{SD}$ ) of $M$. myrmicae larvae found at the beginning of July was $10.1 \pm 5.48 \mathrm{mg}$. The smallest larva weighed $4.7 \mathrm{mg}$ and the heaviest $16.4 \mathrm{mg}$. The first big increase in body mass was recorded in the second half of July and at the end of this month the larvae weighed $89.9 \pm 16.43 \mathrm{mg}$ (Fig. 2). During the next two months (August and September) larvae continued to 


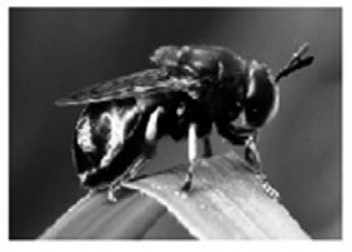

F. Adult

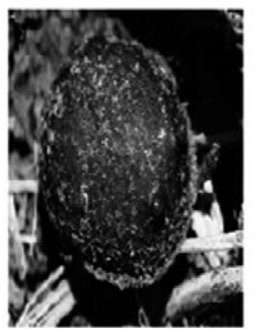

E. Pupa

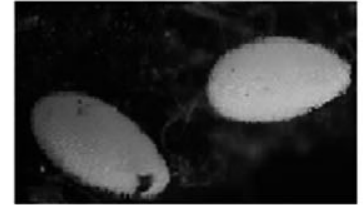

A. Eggs

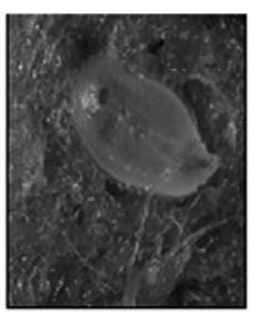

B. $1^{\text {st }}$ instar larva

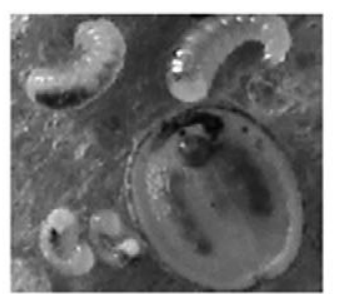

C. $2^{\text {nd }}$ instar larva

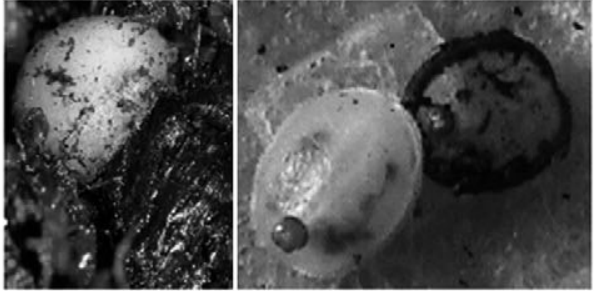

D. $3^{\text {rd }}$ instar larva

\begin{tabular}{|c|c|c|c|c|}
\hline May & June & July-March & April & May \\
\hline $\begin{array}{l}\text { Adults } \\
\text { Eggs }\end{array}$ & I instar & II and III instar & Pupa & $\begin{array}{l}\text { Eggs } \\
\text { Adults }\end{array}$ \\
\hline
\end{tabular}

Fig. 1. The life cycle of Microdon myrmicae. Adult females (F) lay their eggs (A) on the surface of Myrmica nests in May. $1^{\text {st }}$ instar larvae (B) hatch from eggs in June and then moult to $2^{\text {nd }}$ instar larvae (C). $3^{\text {rd }}$ instar larvae (D) spend about 8 months in ants' nest and in April of the following year they pupate (E).

grow rapidly and in the middle of October they weighed on average $125.4 \pm 28.24 \mathrm{mg}$ and the heaviest $157.4 \mathrm{mg}$. Larvae collected after winter were slightly lighter than in the previous autumn with a mean body mass of $113.9 \pm 20.77 \mathrm{mg}$. The average pupal body mass was $100.0 \pm 16.1 \mathrm{mg}$ (Fig. 2, last measurement).

The seven laboratory-reared $M$. myrmicae larvae were recorded feeding on 12 occasions, mostly eating small Myrmica larvae ( 9 cases) or medium-sized ant larvae ( 3 cases) but none fed on ant eggs or large ant larvae.

\section{Number of larvae of social parasites recorded in Myrmica nests}

In total, 200 nests of M. scabrinodis were investigated of which 30 contained larvae of M. myrmicae, 15 Maculinea alcon larvae and 10 Maculinea teleius larvae (Table 1). The highest median number of larvae of $M$. alcon per nest was three (with quartiles of one and four; 1, 4). For M. myrmicae the corresponding values were $2.5(1,4)$ and for M. teleius $1(1,2)$. There were significantly more $M$. myrmicae larvae per Myrmica nest than of M. teleius (Mann-Whitney test, $\mathrm{N}=41, \mathrm{U}=102.5, \mathrm{p}=$ $0.05)$, but no difference in the numbers of $M$. myrmicae and $M$. alcon larvae per host colony (Mann-Whitney test, $\mathrm{N}=45, \mathrm{U}=$ $208, p=0.67)$. The maximum number of larvae found in the same Myrmica nest was 27 M. myrmicae, 13 M. alcon and 5 M. teleius.

\section{DISCUSSION}

We describe the full life cycle of one European species of Microdon and shed some light on the potential effect it has on the fitness of the host-ant colony. M. myrmicae passes through three instars and overwinters as $3^{\text {rd }}$ instar larvae. Our observations show that $M$. myrmicae probably has one generation per year. Immediately before pupation, all larvae were the same size, which strongly suggests that they take a year to develop. These two traits (univoltinism and length of larval development) seem to vary among species of Microdon since, for example, $M$. fuscipennis (Macquart, 1834) has more than one generation per year, whereas M. xanthopilis, Townsend, 1895 is similar to $M$. myrmicae in only having one (Akre et al., 1973; Duffield, 1981). Interestingly, Schönrogge et al. (2000) demonstrate that English populations of M. mutabilis and M. myrmicae include both slow- and fast-developing larvae, which means that some of them complete their development in one and others in two years. This is similar to what is observed for some Maculinea populations, where larval polymorphic development seems to be restricted to some northern and mountainous sites as it has not been recorded in the central and southern parts of their ranges (Nowicki et al., 2009). M. myrmicae populations may also vary 


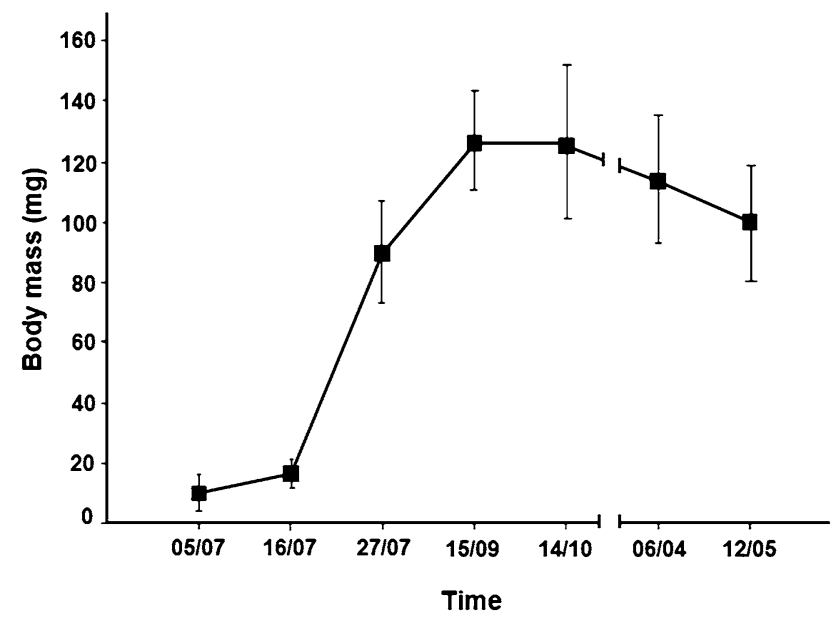

Fig. 2. Trend in the body mass (mean $\pm \mathrm{SD}$ ) of M. myrmicae larvae collected in the field from the beginning of June 2010 till April 2011. The last measurement is the mean body mass of the M. myrmicae pupae collected in May 2011.

with respect to larval polymorphic development, since in some northern areas such as England and Poland (Witek, unpubl. data), two larval cohorts are found, whereas in the southern populations the larvae take only one year to complete their development. Developmental polymorphism may represent an adaptation to life in more unpredictable habitats (Witek et al., 2006).

Myrmica workers did not respond to the eggs and $1^{\text {st }}$ instar larvae of Microdon even when the latter moved towards the nest entrance and entered the nest. This suggests that both the eggs and larvae use "chemical insignificance" to avoid detection by the host ants (Lenoir et al., 2001). In contrast, Duffield (1981) records that $1^{\text {st }}$ instar larvae of $M$. fuscipennis were often detected by workers of their host ant, Iridomyrmex pruinosus (Wheeler, 1913) and carried out of the colony. Garnett et al. (1985) records that in three North American species of Microdon (M. albicomatus Novak, 1977, M. cothurnatus Bigot, 1884, and M. piperi Knab, 1917) the host ants actively transport $1^{\text {st }}$ and the $2^{\text {nd }}$ instar larvae into the deeper parts of the nest, as well as from one brood chamber to another, suggesting that these Microdon larvae are well integrated with their host colony and use either chemical camouflage or mimicry.

The percentage mortality of Microdon $1^{\text {st }}$ instar larvae recorded in this study and by Duffield (1981) in the laboratory was very high. The behaviour of the $1^{\text {st }}$ instar larvae in both this and Duffield's study was very similar in that they were very mobile, moved into the deep parts of the colony and were not observed to feed or be fed by the ants. The feeding behaviour of the $2^{\text {nd }}$ and $3^{\text {rd }}$ instar larvae of M. myrmicae is also similar to that recorded for M. fuscipennis (Duffield, 1981). The fly larvae consumed small- or medium-size ant brood and avoided feeding on large ant larvae or pupae. Interestingly, our field data indicate that M. myrmicae larvae grow quickly during the first four months of their life inside host colonies and reach maximum body mass in September and October, just before overwintering. Moreover, none of the $3^{\text {rd }}$ instar larvae collected in September was seen to feed. Both of these observations suggest that $M$. myrmicae larvae eat only at the beginning of their development in a host colony, whereas during winter and the following early spring they use ant nests only for shelter. The fact that M. myrmicae feeds only on the small or half-grown ant brood may have important consequences for the fitness of the host colony, as well as decreasing inter-specific competition and increasing sur- vival of larvae coexisting within the same host colony. Comparing the median number of $M$. myrmicae larvae found at the end of their larval development with those of two Maculinea butterfly species, with different feeding strategies, in the same host colony (Thomas \& Elmes, 1998) indicates that Microdon is more similar to $M$. alcon (a "cuckoo species" fed by trophallaxis) than $M$. teleius (a predatory species). Although $M$. myrmicae is a predator, as is Maculinea teleius, and feeds directly on ant brood, it is not subject to the same high level of scramble competition as the butterfly larvae. In this study the highest number of larvae of M. myrmicae recorded was found in a single host colony and all were large enough to complete their life cycle. The high percentage of larvae of Microdon that survive is probably due to fact that they feed only on small ant larvae, whereas predatory species of Maculinea prefer to eat large ant brood (Thomas \& Wardlaw, 1992). Additionally, because $M$. myrmicae feeds mostly on the early stages of ant brood it possibly has a smaller negative effect on the host colony than predatory Maculinea. High densities of predatory Maculinea may induce the ant workers to desert their nest, which they do in the absence of brood (Thomas \& Wardlaw, 1992).

Differences in the life cycles of the various species of Microdon may be due to their different host specificities. A better understanding of the biology of other European species of Microdon, coupled with more detailed studies of their chemical and acoustical adaptations, will probably shed some additional light on social parasite-host interactions.

ACKNOWLEDGEMENTS. We would like to thank D. Patricelli and M. Sala for their help with fieldwork, and M. Gherlenda for his help with laboratory experiments and for taking the photographs of Microdon illustrating this article. This research was funded within the project CLIMIT (Climat Change Impacts on Insects and their Mitigation; see Settele \& Kühn, 2009; Thomas et al., 2009) funded by DLR-BMBF (Germany), NERC and DEFRA (UK), ANR (France), Formas (Sweden), and Swedish EPA (Sweden) through the FP6 BiodivERsA Eranet as well as by the project "A multitaxa approach to study the impact of climate change on the biodiversity of Italian ecosystems" of the Italian Ministry of University and Research (MIUR).

\section{REFERENCES}

ANDRIES M. 1912: Zur Systematic, Biologie und Entwicklung von Microdon Meigen. Z. Wissensch. Zool. 103: 300-361.

Akre R.D., Alpert G. \& Alpert T. 1973: Life cycle and behaviour of Microdon cothurnatus in Washington (Diptera: Syrphidae). J. Kans. Entomol. Soc. 46: 327-338.

Akre R.D., Garnett W.B. \& Zack R.S. 1988: Biology and behaviour of Microdon piperi in the Pacific Northwest (Diptera: Syrphidae). J. Kans. Entomol. Soc. 61: 441-452.

Bonelli S., Witek M., Canterino S., Sielezniew M., Stankiewicz A., Tartally A., Balletto E. \& Schönrogge K. 2011: Distribution, host specificity and the potential for cryptic speciation in hoverfly Microdon myrmicae (Diptera: Syrphidae), a social parasite of Myrmica ants. Ecol. Entomol. 36: $135-143$.

Cheng X.Y. \& Thompson F.C. 2008: A generic conspectus of the Microdontinae (Diptera: Syrphidae) with the description of two new genera from Africa and China. Zootaxa 1879: 21-48.

DoczKal D. \& Schmid U. 1999: Revision der mitteleuropäischen Arten der Gattung Microdon Meigen (Diptera, Syrphidae). Volucella 4: 45-68.

DufFIELD R.M. 1981: Biology of Microdon fuscipennis (Diptera: Syrphidae) with interpretation of the reproductive strategies 
of Microdon species found north of Mexico. Proc. Entomol. Soc. Wash. 84: 716-724.

Elmes G.W., Barr B., Thomas J.A. \& Clarke R.T. 1999: Extreme host specificity by Microdon mutabilis (Diptera: Syrphidae), a social parasite of ants. Proc. R. Soc. Lond. 266: 447-453.

Garnett W.B., Akre R.D. \& Sehlke G. 1985: Cocoon mimicry and predation by myrmecophilous Diptera (Diptera: Syrphidae). Fla Entomol. 68: 615-621.

Hölldobler B. \& Wilson E.O. 1990: The Ants. Springer, Berlin, $732 \mathrm{pp}$.

Lenoir A., D'Ettore P., Errard C. \& Hefetz A. 2001: Chemical ecology and social parasitism in ants. Annu. Rev. Entomol. 46: 573-599.

Nowicki P., Bonelli S., Barbero F. \& Balletto E. 2009: Relative importance of density-dependent regulation and environmental stochasticity for butterfly population dynamics. Oecologia 161: 227-239.

SchmiD U. 2004: Microdon rhenanus and Microdon eggeri var. major (Diptera: Syrphidae) revisited. Volucella 7: 111-124.

Schönrogge K., Wardlaw J.C., Thomas J.A. \& Elmes G.W. 2000: Polymorphic growth rates in myrmecophilous insects. Proc. R. Soc. Lond. 267: 771-777.

Schönrogge K., Barr B., Wardlaw J.C., Napper E., Gardner M.G., Breen J., Elmes G.W. \& Thomas J.A. 2002: When rare species become endangered: cryptic speciation in myrmecophilous hoverflies. Biol. J. Linn. Soc. 75: 291-300.

Schönrogge K., Gardner M.G., Elmes G.W., Napper E.K.V., Simcox D.J., Wardlaw J.C., Breen J., Barr B., Knapp J.J., Pickett J.A. \& Thomas J.A. 2006: Host propagation permits extreme local adaptation in a social parasite of ants. Ecol. Lett. 9: 1032-1040.

Schönrogge K., Napper E.K.V., Birkett M.A., Woodcock C.M., Pickett J.A., Wadhams L.J. \& Thomas J.A. 2008: Host recognition by the specialist hoverfly Microdon mutabilis, a social parasite of the ant Formica lemani. J. Chem. Ecol. 34: 168-178.

Settele J. \& Kühn E. 2009: Insect conservation. Science 325: $41-42$.

Thomas J.A. \& Elmes G.W. 1998: Higher productivity as the cost of increased host-specificity when Maculinea butterfly larvae exploit ant colonies through trophallaxis than by predation. Ecol. Entomol. 23: 457-464.

Thomas J.A. \& WardLAW J.C. 1992: The capacity of a Myrmica ant nest to support a predacious species of Maculinea rebeli inhabitants in ant nests. Oecologia 91: 101-109.

Thomas J.A., SchönRogge K. \& Elmes G.W. 2005: Specialization and host associations of social parasites of ants. In: Fellowes M.D.E., Holloway G.J. \& Rolff J. (eds): Insect Evolutionary Ecology. CABI, Wallingford, pp. 475-514.

Witek M., Sliwinska E.B., Skórka P., Nowicki P., Settele J. \& WoYcIECHOWSKI M. 2006: Polymorphic growth in larvae of Maculinea butterflies, as an example of biennialism in myrmecophilous insects. Oecologia 148: 729-733.

Witek M., Particelli D., Casacci L.P., Barbero F., Balletto E. \& Bonelli S. 2011: Notes on the biology and host ant specificity of the myrmecophilous syrphid fly Microdon major (Diptera: Syrphidae), a social parasite of Formica ants (Hymenoptera: Formicidae). Sociobiology 57: 261-269.

Received November 18, 2011; revised and accepted February 24, 2012 